\title{
Inorganic Pollutants in Recovered Wood from Slovenia and Boards Made of Disintegrated Wood
}

\author{
Miha Humar* \\ University of Ljubljana, Biotechnical Faculty, Department for Wood Science and Technology, Jamnikarjeva 101, SI- \\ 1000 Ljubljana
}

\begin{abstract}
Due to increasing demands on wood, recovered wood is becoming more and more important. It is mainly used for energetic purposes and for particle board production. This material was polluted with various chemicals (surface coatings, biocides, concrete residues, etc.) during service life. These chemicals causes difficulties at the end of service life. In order to elucidate presence of inorganic pollutants in Slovenian recovered wood, 30 specimens were collected on city Ljubljana dump/sorting site, and analysed with $\mathrm{x}$-ray fluorescence spectrometer (XRF). Those values were compared to the concentration of inorganic elements in boards made of disintegrated wood collected in Slovenian market. In recovered wood, as well as in imported particle boards increased concentrations of the following elements was confirmed: $\mathrm{Cl}, \mathrm{Cr}$, $\mathrm{Fe}, \mathrm{Cu}, \mathrm{Zn}$ and $\mathrm{Pb}$. This indicates that at lest part of contaminated recovered wood is used for production of some particle boards.
\end{abstract}

Keywords: Pollutants, biocides, XRF, particle boards, recovered wood.

\section{INTRODUCTION}

Each product has limited service life, including wooden products. At the end of this service life there is an issue what to do with recovered wood, for example. This material is becoming more and more important, due to limited and more expensive fuel, oil predominately [1]. In Europe, recovered wood is used for various purposes, but energetic and for particle board production are the most important end uses [2]. Disposal of recovered wood to land-fields is not desired according to the EU regulations and it is expected that it will be banned in the near future. The main reason for this decision is fact, that there are considerable amounts of methane (green house gas) emitted during anaerobic degradation of wood in land-fields [3]. In spite of this directive, considerable amounts of wood are still land-fielded, and part of it is used for energetic purposes under non-controlled conditions (Fig. 1).

All problems related to recovered wood, originates from contamination during production process or within service life. It is rather difficult to find wooden products that were not either glued, surface coated or treated with biocides. Wood from construction and demolition sites is frequently contaminated with concrete residues, oxidized iron, etc. as well. All this chemicals can cause difficulties at the end of service life (Table 1) [4].

Arsenic compounds are one of the most problematic compounds in recovered wood. Arsenic was used for wood

*Address correspondence to this author at the University of Ljubljana, Biotechnical Faculty, Department for Wood Science and Technology, Jamnikarjeva 101, SI-1000 Ljubljana; Tel: +386 1423 1161; Fax: +386 1423 5035; E-mail: miha.humar@bf.uni-lj.si preservation for almost half of the $20^{\text {th }}$ century. Common abbreviation for this preservative based on $\mathrm{Cu}, \mathrm{Cr}$ and $\mathrm{As}$ is CCA. It is foreseen, that there will be approximately $8 \%$ of the recovered wood in 2020 contaminated with CCA preservatives in the UK [5]. If arsenic treated wood is burned up at temperatures above $275^{\circ} \mathrm{C}$, solid arsenic compounds are transformed into volatile arsenic oxides. There are numerous reports on cancer and other types of diseases at people in UK and US, that utilised CCA treated wood as energy source for heating and cooking in the past [6]. Fortunately, arsenic compounds were removed from the market almost 20 years ago within most of the continental Europe [7]. However, there are considerable amounts of wood treated with chlorine containing wood preservatives, glues, or surface coatings. In case of uncontrolled incineration of chlorine containing wood, there is a possibility that extremely toxic dioxins are formed. Furthermore, considerable amounts of wood is treated with biocides or surface coatings based on heavy metals like; copper, chromium, zinc, lead, tin... Those compounds remained in the ash after incineration, and such ash must be deposited in approved lad-field sites.

Considerable amounts of recovered wood ( 3 million $t$ year $^{-1}$ in EU) are used for particle board production, particularly in Belgium, Spain, Germany, Italy, UK and Denmark [1]. European panel federation (EPF) prepared voluntary standards for raw material for panel boards production, where maximal concentrations for selected, most frequent, pollutants are defined (Table 1). Despite of this recommendations, there are several particle board producers that do not respect those limits and uses non-suitable raw-material as well, predominately due to increasing prices of wood on the market [2]. In general, inorganic compounds does not present considerable threat for the users, but it is believed, that customers should be informed whether purchased furniture 


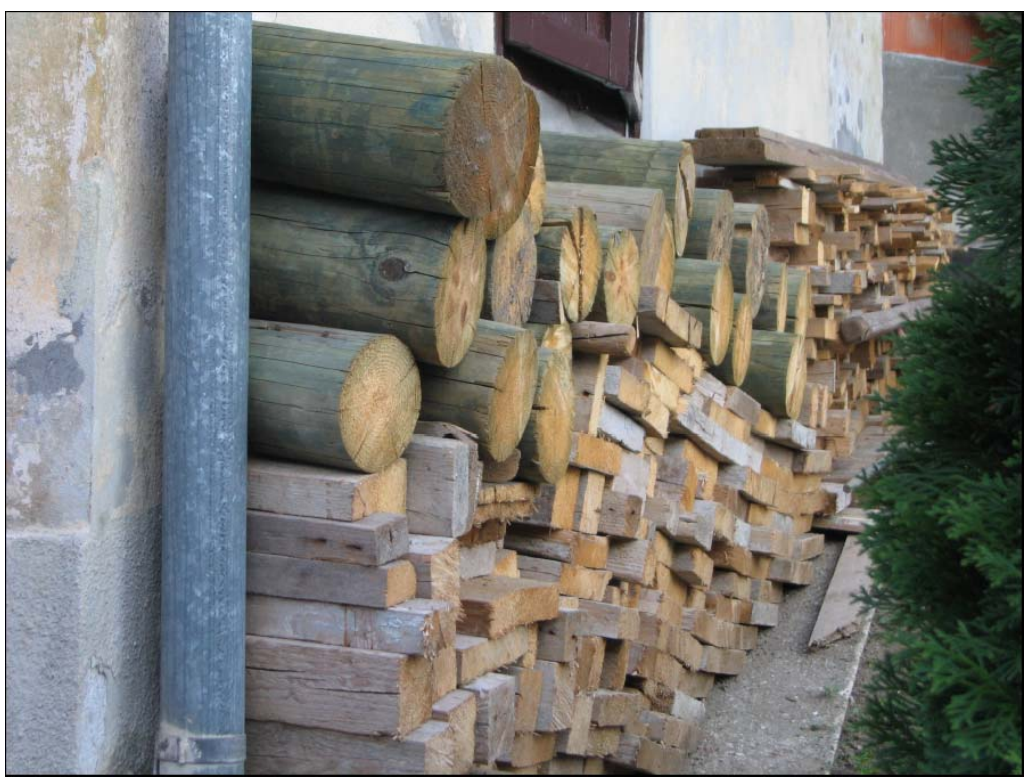

Fig. (1). Copper treated old electricity poles prepared for uncontrolled burning.

Table 1. Origin of the Pollutants in the Recovered Wood, Threshold Values for Particle Board Production and for Fuel Applications Compared to Average Values in Non-Contaminated Wood

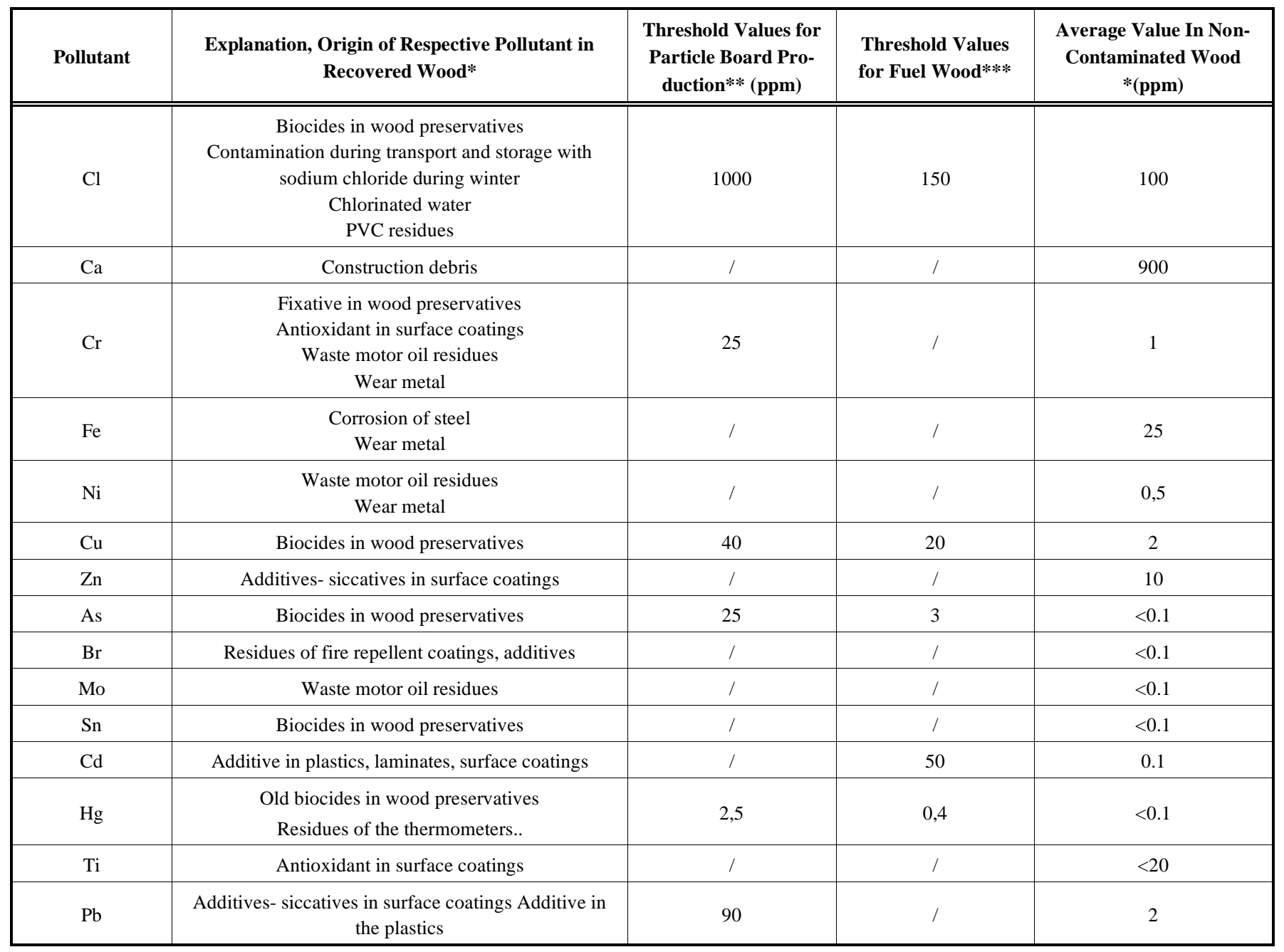




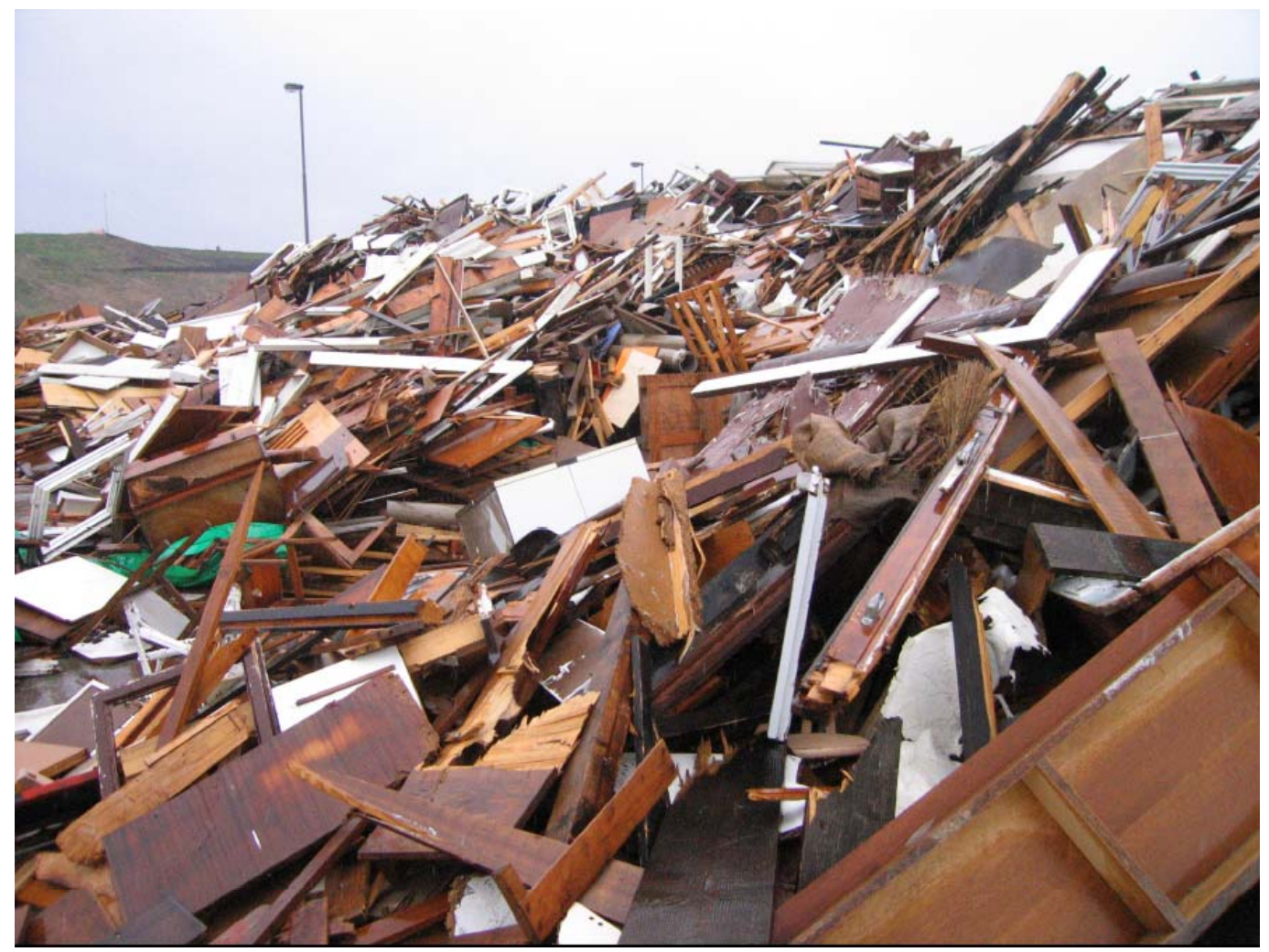

Fig. (2). Variety of recovered wood on the temporary dump site.

contains residues of biocides or not. Secondly, this material will have limited service life as well. Threshold values, for hazard fuels are in some countries lower than EPF recommendations [8]. Therefore, it might happen that consumers will have to pay to get rid of their "toxic furniture" in the future. Thirdly, it should not be forgotten, that in famous action of WWF, 76 different chemicals (biocides, phthalates, fire or flame retardants...) was proved in the blood of European parliament members [9]. It has to be considered, that average parliament member did not work in the industry, and they do not live in the extremely polluted environment. At least part of those chemicals was introduced to the body in the working and living environment. Therefore, it is believed that non-necessary contact with potentially dangerous chemicals should be avoided in all stages.

The objective of this paper is to elucidate the presence of contaminants in recovered wood. In the second part concentrations of selected contaminants in particleboards was determined, as recovered wood is becoming more and more important source in particleboard industry. Measured concentrations are evaluated from legislation point of view.

\section{MATERIAL AND METHODS}

In Slovenian wood manufacturing companies fifteen specimens of boards made of disintegrated wood, from five different producers were collected. Three groups of boards were produced in Slovenia (particle board III, MDF (medium density fibreboard) and HDF (high density fibreboard). Particle board I and II were produced in well known Euro- pean companies. Boards were collected in September 2007. In parallel, 30 specimens of recovered wood from waste sorting site were collected (Fig. 2). There was a lot of wood from various applications. The majority of the wood came from the demolition sites, windows, fences, poles, decking, etc. Most of the collected wooden specimens were surface treated with various treatments. Collected specimens were documented, oven dried $\left(24 \mathrm{~h} ; 103^{\circ} \mathrm{C}\right)$ milled with laboratory mill (IKA) and pressed into tablets $(\mathrm{r}=16 \mathrm{~mm} ; \mathrm{d}=5$ $\mathrm{mm}$ ) with Chemplex press for further analysis.

For analysis X-ray fluorescence spectroscopy was applied (XRF, TwinX, Oxford instruments). In the first step qualitative analysis was performed. The most frequent pollutants were identified. For those elements calibration curves were prepared and in the second step quantitative analysis was carried out. Most of the measurements were performed on PIN detector $(\mathrm{U}=26 \mathrm{kV}, \mathrm{I}=115 \mu \mathrm{A}, \mathrm{t}=300 \mathrm{~s})$. However, chlorine concentration was determined with proportional detector in helium atmosphere.

\section{RESULTS AND DISCUSSION}

Qualitative analysis of the recovered wood specimens confirmed the presence of the following elements: chlorine, chromium, iron, copper, zinc, bromine, titan, lead and strontium (Fig. 3). Concentration of those elements in control, fresh wood (mixture of beech and Norway spruce wood) was below detection limits (Table 3). Fortunately, there was no arsenic, tin or mercury determined in any of the analysed specimens. 


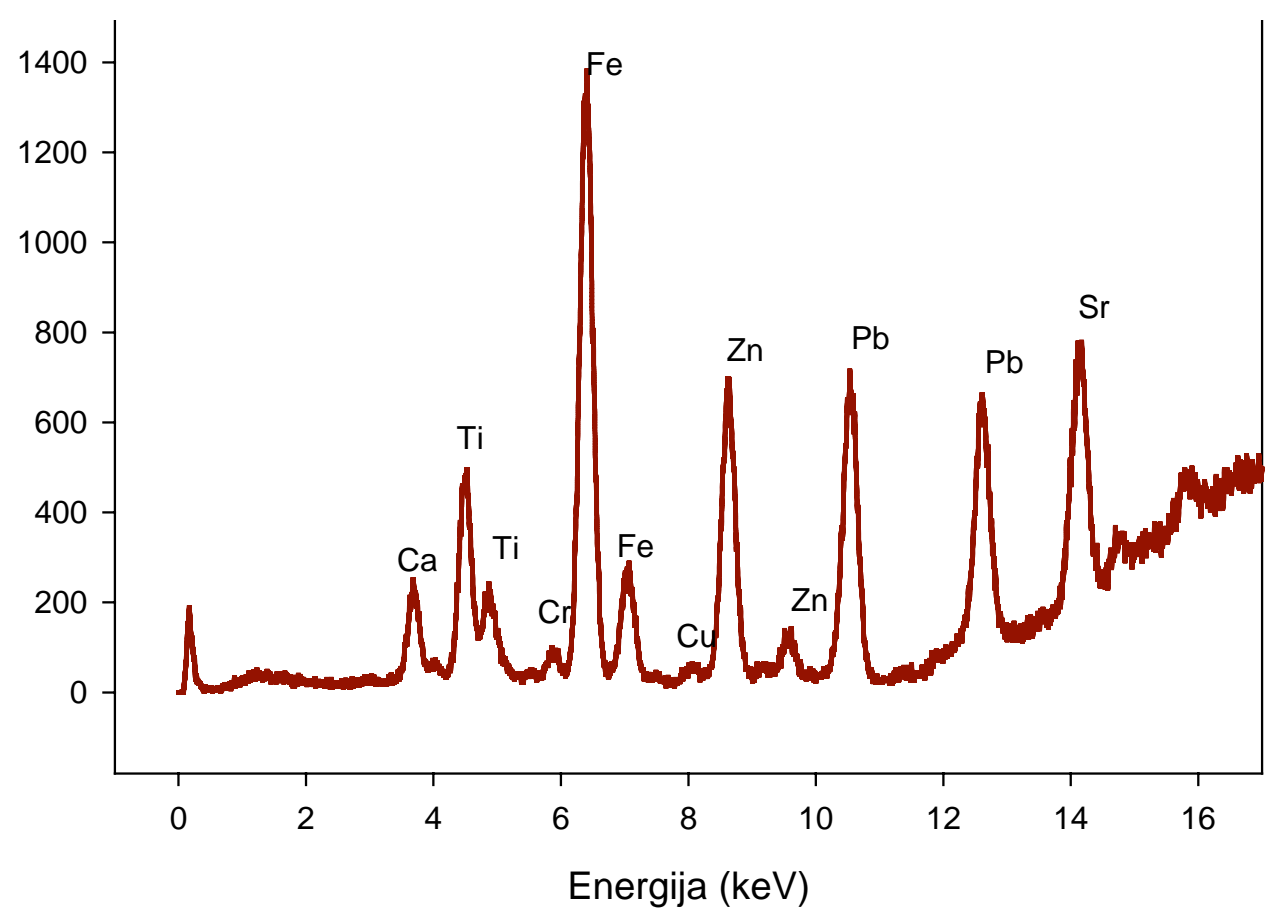

Fig. (3). XRF spectra of contaminated recovered wood sample.

On the basis of the literature data [10,11], visual estimation of the samples and data in the table 1 it is presumed, that the reason for increased concentration of inorganic pollutants originates in surface coatings $(\mathrm{Zn}, \mathrm{Ti}, \mathrm{Pb})$, biocide treatments $(\mathrm{Cr}, \mathrm{Cu}$ and partially $\mathrm{Cl}$ ), gluing (partially $\mathrm{Cl})$, steel corrosion $(\mathrm{Fe}$ and $\mathrm{Cr}$ ), fire retardant additives $(\mathrm{Br})$. In one of the specimens even strontium was determined (Fig. 2). According to the available data [12], strontium is not used in the field of wood technology. Therefore, it is presumed, that wood was polluted with strontium on the collection site. The most important strontium application is (was) production of classical CRT screens for TV or monitors. It can be presumed, that one of those screens was demolished near analysed specimen, what consequently resulted in polluted wood.

Zinc, was the chemical element that was present in the highest number of the analysed specimens of recovered wood. In average, there was $910 \mathrm{ppm}$ of zinc determined in collected recovered wood. The highest concentration was determined in specimen no 10 , where $7545 \mathrm{ppm}$ of $\mathrm{Zn}$ was measured. This sample used to belong to the window frame, and was surface treated with white alkyd surface coating. It was evident, that this window was brushed for several times, as there were several layers visible. Besides zinc, chlorine $(716 \mathrm{ppm})$ and iron $(553 \mathrm{ppm})$ were the second most frequent pollutants determined. The main reason for high iron content is corrosion of steel elements in contact with wood (fasteners, metal parts...) as at least the smallest steel parts were not separated from the recovered wood. Among all pollutants determined, iron is one of the least problematical elements in recovered wood. In contrary to iron, chlorine causes more problems. Among 30 analysed specimens, 7 of them exceed limit (1000 ppm) for raw material for particle board production [8], and almost all of the analysed speci- mens contains too much chlorine $(150 \mathrm{ppm})$ to be used for energetic purposes according to the Slovenian legislation [13] (Table 2). Even the specimens that contains more than $1000 \mathrm{ppm}$ of $\mathrm{Cl}$, does not have common properties, with exception that all of them were surface coated. There is several possible explanations for high chlorine content; biocides in surface coatings (quaternary ammonium compounds, isothiazolones...), transport (use of sodium chloride during winter), chlorinated water... [10,11].

There was considerably higher concentration of lead determined in recovered wood as well. Analysed specimens in average contain $79 \mathrm{ppm}$ of lead. More than $25 \%$ of the collected specimens contained more than $90 \mathrm{ppm}$ of the lead, what is limit for the raw material in particle board industry. The highest concentration of lead (451 ppm) was determined in specimen 24, treated with dark surface coating (Table 2). However, there was considerably less copper $(67 \mathrm{ppm})$ and chromium $(10 \mathrm{ppm})$ determined in average. It was expected that concentration of chromium and copper will correlate, as those two compounds were usually used in the same preservative solution. However, visual analysis of the specimens resolved that high copper concentrations were measured in specimens with thick surface coatings, where copper was added predominately as pigment, biocide or siccative [11]. The only specimen that was impregnated with copper based wood preservative was specimen no 26 (958 ppm). This specimen was probably treated with novel generation of copper-amine wood preservatives, as there was no chromium determined in this specimen.

However, it was of the significant interest, if the inorganic pollutants determined in the recovered wood from sorting facilities will occur in the panels in the Slovenian market as well. According to the data obtained, panels can be di- 
Table 2. Concentration of Selected Elements in the Recovered Wood Samples

\begin{tabular}{|c|c|c|c|c|c|c|c|}
\hline \multirow{2}{*}{ Sample } & \multicolumn{7}{|c|}{ Pollutant Concentration (ppm) } \\
\hline & Cl & $\mathrm{Cr}$ & $\mathbf{F e}$ & $\mathrm{Cu}$ & $\mathbf{Z n}$ & $\mathbf{B r}$ & $\mathbf{P b}$ \\
\hline Control & 0 & 0 & 0 & 0 & 0 & 0 & 0 \\
\hline 1 & 354 & 0 & 581 & 6 & 37 & 0 & 0 \\
\hline 2 & 306 & 0 & 44 & 0 & 22 & 0 & 5 \\
\hline 3 & 3697 & 0 & 690 & 51 & 1583 & 0 & 53 \\
\hline 4 & 0 & 0 & 10 & 0 & 9 & 0 & 6 \\
\hline 5 & 201 & 0 & 165 & 0 & 21 & 0 & 18 \\
\hline 6 & 175 & 0 & 49 & 0 & 15 & 0 & 0 \\
\hline 7 & 296 & 0 & 44 & 5 & 80 & 0 & 53 \\
\hline 8 & 781 & 0 & 176 & 110 & 3006 & 0 & 83 \\
\hline 9 & 227 & 0 & 58 & 114 & 3755 & 0 & 115 \\
\hline 10 & 1037 & 0 & 226 & 252 & 7545 & 0 & 122 \\
\hline 11 & 619 & 0 & 461 & 34 & 1106 & 0 & 245 \\
\hline 12 & 651 & 0 & 107 & 185 & 6082 & 5 & 77 \\
\hline 13 & 304 & 0 & 86 & 0 & 15 & 0 & 17 \\
\hline 14 & 1226 & 0 & 1841 & 19 & 426 & 6 & 254 \\
\hline 15 & 466 & 260 & 1601 & 146 & 28 & 0 & 7 \\
\hline 16 & 290 & 0 & 64 & 0 & 9 & 0 & 5 \\
\hline 17 & 177 & 0 & 541 & 0 & 35 & 0 & 8 \\
\hline 18 & 611 & 0 & 72 & 8 & 48 & 0 & 0 \\
\hline 19 & 394 & 0 & 419 & 0 & 19 & 0 & 8 \\
\hline 20 & 1463 & 0 & 149 & 0 & 23 & 0 & 7 \\
\hline 21 & 406 & 0 & 474 & 0 & 16 & 0 & 81 \\
\hline 22 & 877 & 0 & 551 & 9 & 235 & 0 & 57 \\
\hline 23 & 1257 & 0 & 532 & 74 & 2548 & 0 & 98 \\
\hline 24 & 605 & 0 & 2366 & 11 & 101 & 13 & 451 \\
\hline 25 & 1627 & 25 & 2928 & 11 & 302 & 0 & 347 \\
\hline 26 & 1108 & 0 & 326 & 958 & 61 & 0 & 24 \\
\hline 27 & 451 & 15 & 644 & 6 & 65 & 0 & 25 \\
\hline 28 & 633 & 0 & 240 & 0 & 17 & 0 & 12 \\
\hline 29 & 644 & 0 & 509 & 5 & 94 & 6 & 161 \\
\hline 30 & 601 & 0 & 639 & 5 & 9 & 0 & 19 \\
\hline average & 716 & 10 & 553 & 67 & 910 & 1 & 79 \\
\hline
\end{tabular}

Remark: Value 0 indicates, that the concentration of analysed element was below detection limit.

vided into two groups (Table 3 ). In the first group (particle board III, MDF and HDF), there was no increased concentrations of possible contaminants observed, with exception of slightly increased iron concentrations. It is presumed that the reason for this increase originates from the wear of metals during milling, cutting grinding of the particles during production process. There was slightly increased chlorine con- centrations observed as well. The reason for chlorine might be additives and catalyst in glue, sodium chloride, and chlorinated industrial water... In the second group (particle board I and II), particle board contained considerably higher concentrations of pollutants. The highest concentration was determined in particle board I, which contained $70 \mathrm{ppm}$ of zinc, $4 \mathrm{ppm}$ bromine, $29 \mathrm{ppm}$ of lead, $8 \mathrm{ppm}$ of copper and 981 
Table 3. Concentration of Selected Elements in Boards Made of Disintegrated Wood

\begin{tabular}{|c|c|c|c|c|c|c|c|}
\hline \multirow{2}{*}{ Sample } & \multicolumn{9}{|c|}{ Pollutant Concentration (ppm) } \\
\cline { 2 - 8 } & $\mathbf{C l}$ & $\mathbf{C r}$ & $\mathbf{F e}$ & $\mathbf{C u}$ & $\mathbf{Z n}$ & $\mathbf{B r}$ & $\mathbf{P b}$ \\
\hline \hline Particle board I & 981 & 0 & 676 & 8 & 79 & 4 & 29 \\
\hline Particle board II & 634 & 0 & 250 & 0 & 43 & 0 & 11 \\
\hline Particle board III & 335 & 0 & 183 & 0 & 0 & 0 \\
\hline MDF & 180 & 0 & 151 & 0 & 8 & 0 \\
\hline HDF & 153 & 0 & 52 & 0 & 6 & 0 \\
\hline
\end{tabular}

ppm of chlorine. Those values are rather high, and indicate that there was non suitable raw material used for production of particle boards as well. In one board even bromine was determined, that is used for fire retardant applications.

\section{CONCLUSIONS}

Half of the wood specimens collected from sorting site, is too polluted to be used for particle boards production or to be used for energetic purposes according to the Slovenian legislation. The most important pollutant found in recovered wood was $\mathrm{Cl}, \mathrm{Zn}$ and $\mathrm{Pb}$. Chemical analysis of the particle boards from Slovenian market revealed, that some of the imported boards contains significant concentrations of pollutants, what indicates that they are produced from nonsuitable raw material. There should be more control performed on the use of contaminated wood for particle board production.

\section{ACKNOWLEDGEMENTS}

The authors would like to acknowledge the Slovenian Research Agency for financial support in the frame of the projects L4-0820-0481 and P4-0015-0481. Technical support of Jurij Hladnik is appreciated.

\section{REFERENCES}

[1] J. Van Acker and C. Van Riet, "Recovered wood for wood-based panels". Joint Workshop COST action E31/E37, 2005, p. 12. ment of Recovered Wood Recycling, Bioenergy and Other Options. 2004, pp. 143-156.

[3] Directive on the landfill of waste 1999/31/EEC. Official Journal of the European Communities, L 182/1.

[4] A. Merl, "Sustainable Resource Management in the Building Sector - management of Recovered Wood in the City of Vienna". In: C. Gallis, Eds. Management of Recovered Wood Recycling, Bioenergy and Other Options. 2004, pp. 136-142.

[5] R. Murphy, P. McQuillan, J. Jermer, and R.D. Peek, "Preservative Treated Wood as a Component in the Recovered Wood Stream in Europe - A Quntitative and Qualitative Review. In: C. Gallis, Eds. Management of Recovered Wood Recycling, Bioenergy and other Options, 2004, pp. 169-189.

[6] T.G. Townsend, and H.M. Solo-Gabriele, Environmental Impacts of Treated Wood. UK: CRC/Taylor \& Francis, 2006, p. 501.

[7] Pohleven, F. The current status of use of wood preservatives in some European countries - summary of the answers to the questionnaire - the last correction in February 1998, Brussels, COST E2, 1998, p. 2.

[8] EPF, "EPF Industry standard. The use of recycled wood for woodbased panels" 2004, p. 3

[9] WWF, "European parliamentarians contaminated by 76 chemicals", http://www.panda.org/about_wwf/what_we_do/policy/ toxics/ news/index.cfm?uNewsID=12622 (31.1.2008), 2004.

[10] J. Krook, A. Martensson, and M. Eklund, "Sources of heavy metal contamination in Swedish wood waste used for combustion". Waste Manage, vol. 26, pp. 158-166, 2006.

[11] $\mathrm{prCEN} / \mathrm{TS} 14961$ "Solid Biofuels -Fuel specification and classes", 2004.

[12] Strontium. 31, Jan, 2004; Available at: http://www.chemnetbase. com/periodic_table/elements/ strontium.htm

[13] Slovenian governmental ordinance on transformation of nonhazardous wastes to solid fuels. Off J Republic Slovenia, vol. 57, pp. $6210-6224,2008$. (http://creativecommons.org/licenses/by-nc/3.0/g) which permits unrestricted, non-commercial use, distribution and reproduction in any medium, provided the work is properly cited. 